\section{Geo-engineering might cause, not cure, problems}

SIR - James E. Lovelock and Chris G. Rapley, in their Correspondence 'Ocean pipes could help the Earth to cure itself' (Nature 449, 403; 2007) propose a variant on some well-publicized schemes to remove carbon dioxide from the atmosphere, by fertilizing the surface waters of the ocean (see also Nature doi:10.1038/news070924-8; 2007). All such schemes suffer from a major problem, because simply enhancing the growth of phytoplankton is not enough. It is the sinking flux of particulate organic carbon into the deep ocean - and ideally into the sediments (usually a small fraction of the total primary production) - that must be enhanced for sequestration to be effective.

Several recent open-ocean experiments have attempted to quantify the level of growth enhancement and sequestration caused by purposeful fertilization: for example, by iron, an essential micro-nutrient. Despite successfully increasing plant biomass, these have not demonstrated sequestration of carbon into the deep ocean (below 1,000 metres), which is essential if it is to be isolated from the atmosphere for centuries or longer. The sinking particles carrying this carbon are degraded rapidly by respiration, and mostly remineralized within the upper ocean. It is likely that almost all the $\mathrm{CO}_{2}$ taken up is released back to the atmosphere within a year. Also, this scheme would bring water with high natural $p_{\mathrm{CO}_{2}}$ levels (associated with the nutrients) back to the surface, potentially causing exhalation of $\mathrm{CO}_{2}$.

We support efforts to find ways of sequestering carbon, but the likely consequences of geo-engineering schemes should be thoroughly researched before they are promoted as solutions. We do not consider ocean fertilization to be a promising approach, and on a large scale it would constitute major interference with an ecosystem which is still poorly understood. Fertilization is likely to alter the phytoplankton community composition and succession, and thus the structure of the oceans' food webs. It might damage these remote and possibly fragile ecosystems, trigger unexpected feedbacks and even reduce their ability to sequester carbon. We cannot, therefore, support this approach, until it can be shown that there would be demonstrable benefits which would outweigh the potential impacts.

John Shepherd, Debora Iglesias-Rodriguez, Andrew Yool

National Oceanography Centre, Southampton, SO14 3ZH, UK

See Nature Reports Climate Feedback http://blogs.nature.com/climatefeedback/ 2007/09/lovelock_and_rapley_propose_ cu_1.html and the Nature newsblog at http://blogs.nature.com/news/blog/2007/ 09/mixing_the_oceans_proposed_to.html for further comments on Lovelock and Rapley's Correspondence; you are welcome to add your own views - Editor, Nature.

\section{Heavy workload may have led to mistakes in review}

SIR - Michael M. Crow, president of Arizona State University, is renowned for striving to make his institution the biggest in the United States while raising its relatively low academic standing. His impartiality may be open to question as a reviewer of my book Science for Sale: The Perils, Rewards, and Delusions of Campus Capitalism (Nature 449, $405 ; 2007$ ), which is sceptical of such quests. Its epilogue, 'A parable for our time', caricatures the headlong pursuit of academic greatness.

Not open to question, however, are Crow's misrepresentations. Nowhere do I assert "that the academic scientist and the university are best motivated by curiosity alone". I do report an interview I conducted in which a scientist makes that assertion, followed by my rejoinder challenging the concept. And, contrary to Crow's assessment, I do not ignore or disparage the long history of practical research in universities: I go into considerable detail on this subject.

I prefer to believe that hasty reading by a heavily burdened university president accounts for these errors and omissions. Daniel S. Greenberg

3736 Kanawha St. Nw.,

Washington DC 20015-1874, USA

\section{Funding basic research brings unexpected benefits}

SIR - The United Kingdom's research base has seen unprecedented increases in public investment in recent years, mostly predicated on the long-term benefits to society expected to arise from that investment. It is the research councils' responsibility, as the major public funders of UK research, to provide compelling evidence that these expectations are being met. Your Editorial 'Innovation versus science?' (Nature 448, 839; 2007) concludes that efforts to document this herald a shift away from our support for basic research. As a research council chief executive, leading our efforts to increase our economic impact, I can say that is not the case.

The UK Research Councils have just published a report, Excellence with Impact (www.rcuk.ac.uk/innovation/impact) that looks across research councils' investments. Each of 18 case studies shows actual and/or potential impact, ranging from biotech spinouts and skilled engineers to climate-change policy. Probably the most reassuring finding was the extent to which some demonstrated multiple types of impact. Furthermore, many of the impacts were not necessarily part of the original rationale for the specific investment, suggesting that serendipity and opportunism are important factors for the research councils. Investment in DNA technologies, for example, did not anticipate the forensic power of DNA fingerprinting, and polymer research was not funded with the anticipation that it would create a new market in flexible displays.

These results demonstrate the wisdom of the research councils' commitment to funding excellent basic research. Rather than weaken that commitment, our approach is to embed economic-impact considerations in our organizations, thus shifting the central focus of the research councils to excellent research with high economic impact. So it is about what basic research we should fund, rather than if we should fund it.

Philip Esler

Arts and Humanities Research Council,

Whitefriars, Lewins Mead, Bristol BS12AE, UK

\section{One-vesicle hypothesis has been extensively discussed}

SIR - Your News story 'Long-held theory is in danger of losing its nerve ${ }^{1}$ described a published criticism of work we published 25 to 26 years ago and our reply (references are in ref. 1). In it, you quote unnamed experts who maintain that much of the published work that might be consistent with the one-vesicle hypothesis addressed in the News story has problems.

Recognizing that this News story was not a scientific article, we think it is important to clarify that our work, and that hypothesis, have been discussed extensively in the literature and in public forums ${ }^{2}$, including the exchange of data and analytical tools with another laboratory (see ref. 3). Data consistent with it have also been published quite recently ${ }^{4}$. We all now recognize that neurotransmitter chemical release at synapses is heterogeneous and may function differently in different biological systems. Henri Korn ${ }^{\star}$, Donald Fabert', Antoine Trillerł, Alain Mallets

*INSERM, Institut Pasteur, Paris, France $\uparrow$ Department of Neuroscience, Albert Einstein College of Medicine, Bronx, New York, USA †iologie cellulaire de la Synapse, Inserm U497, Ecole Normale Supérieure, 75005 Paris, France sDépartement de Biostatistiques et Biomathématiques, Université Pierre et Marie Curie-Paris 6, France

\footnotetext{
Nature 449, 124-125 (2007).

2. Central Synapses: Quantal Mechanisms and Plasticity (eds. Faber, D. S. et al.) HFSP, Strasbourg (1998)

3. Redman, S. Physiol. Rev. 70, 165-198 (1990).

4. Silver, R. A. et al. Science 302, 1981-1984 (2003)
} 